\title{
¿̇EXISTE UN DEBER JURÍDICO DE SOPORTAR LOS PERJUICIOS PRODUCIDOS POR UN ACTO ADMINISTRATIVO DECLARADO NULO POR SENTENCIA FIRME?
}

\author{
TOMÁS-RAMÓN FERNÁNDEZ \\ Universidad Complutense de Madrid
}

Resumen

Se analiza críticamente la jurisprudencia del Tribunal Supremo sobre la responsabilidad patrimonial de la Administración por los dańos producidos por actos y resoluciones suyos declarados nulos por sentencia firme.

\section{Palabras clave}

Responsabilidad patrimonial de la Administración; actos discrecionales; perjuicio antijurídico.

\footnotetext{
1 Catedrático emérito.
} 


\section{Abstract}

In this article the author analyzes the decisions of the Supreme Court in the twenty last years about the responsibility of the Administration derived of their own resolutions previously invalidated by the Courts.

\section{Keywords}

Economic responsibility of the Administration; discretionary power; illegal prejudice. 


\section{SUMARIO}

I. INTRODUCCIÓN. II. EL ORIGEN DE LA DOCTRINA: LA SENTENCIA DE 5 DE FEBRERO DE 1996. III. LA EXTENSIÓN POSTERIOR DE LA JURISPRUDENCIA INICIAL: LAS SENTENCIAS DE 16 DE FEBRERO DE 2009 Y DE 20 DE FEBRERO DE 2012. IV. ANÁLISIS CRÍTICO DE LA JURISPRUDENCIA: 1. Un nuevo sistema de responsabilidad por culpa. Y por culpa grave, además. 2. Una contradicción en los términos. 3. Una flagrante violación de la santidad de la cosa juzgada. 4. La ley del embudo.

\section{INTRODUCCIÓN}

La jurisprudencia contenciosa-administrativa dista mucho de ser un jardín cuidado con esmero por un jardinero diligente que se esfuerza en eliminar las malas hierbas apenas las ve despuntar. Más bien se trata, como es notorio, de una frondosa jungla a la que, además, se añaden cada año miles de plantas nuevas, lo que propicia la aparición cuando y donde menos se espera de las especies más insospechadas que contra todo pronóstico crecen desmesuradamente amenazando con asfixiar y destruir otras más delicadas que ha costado decenas de años aclimatar.

La convocatoria frecuente del Pleno de la Sala $3^{\text {a }}$ del Tribunal Supremo por los últimos presidentes de la misma ha contribuido a limitar con toda seguridad las consecuencias del fenómeno al que aludo, pero no ha podido neutralizarlo del todo, ni mucho menos, como lo prueba la doctrina, muy extendida ya, que me propongo analizar.

La pregunta que sirve de título a estas páginas indica con claridad de qué se trata, por lo que puedo proponer sin más al lector, si alguno llego a tener, que antes de continuar leyendo haga un alto y adelante su propia respuesta. ¿Puede decirse, en efecto, que tenga el deber jurídico de soportar las consecuencias perjudiciales que para él hayan podido derivar de un acto administrativo declarado nulo por sentencia firme?

Estoy absolutamente seguro de que la respuesta será unánimemente negativa. Los lectores de esta revista saben muy bien que «la simple anulación en vía administrativa o por los Tribunales contenciosos de las resoluciones administrativas no presupone derecho a indemnización», porque así lo aclaró 
hace ya sesenta ańos el art. 40.2 de la Ley de Régimen Jurídico de la Administración del Estado, texto refundido de 26 de julio de 1957, pero saben también que si el acto declarado nulo les ha producido realmente un daño efectivo y evaluable económicamente, tienen derecho a ser compensados en su integridad hasta quedar totalmente indemnes, porque así se lo garantiza hoy el art. 106.2 de la Constitución.

¿Y si el acto anulado que produjo el daño fue dictado en ejercicio de una potestad discrecional? La respuesta seguiría siendo negativa con toda seguridad. ¿Por qué voy a tener que soportar yo — me diría el lector- el daño que me ha producido un acto administrativo que una sentencia firme ha declarado contrario a derecho? ¿Qué más da que el acto provenga de una potestad reglada o de una potestad discrecional si ha sido declarado nulo por una sentencia firme? ¿Acaso estás insinuando — me diría - que yo estoy jurídicamente obligado a soportar los dańos producidos por un acto declarado no conforme a derecho? ¿En qué ley está escrita esa supuesta obligación? En la Constitución no, por supuesto. Y tampoco en ninguna de las leyes administrativas, ni, desde luego, en el Código Civil, porque, discrecional o no, si el acto ha sido anulado por sentencia firme es porque la Administración que lo dictó no lo hizo bien y actuó, por lo menos, de forma poco diligente, lo que el art. 1902 del Código Civil, recogiendo una experiencia de veinte siglos, condena irremisiblemente ("el que por acción u omisión causa daño a otro, interviniendo culpa o negligencia, está obligado a reparar el dańo causado»).

Pues bien, no es esa, lector amigo, la opinión de la Sala $3^{\text {a }}$ del Tribunal Supremo, como voy a mostrar a continuación.

\section{EL ORIGEN DE LA DOCTRINA: LA SENTENCIA DE 5 DE FEBRERO DE 1996}

La cuestión viene ya de lejos. Una sentencia de 25 de mayo de 2004, con la que me tropecé al redactar una addenda para la $5^{\mathrm{a}}$ edición de mi libro De la arbitrariedad de la Administración, casó y anuló la dictada por el Tribunal Superior de Justicia de Cataluña que había estimado el recurso interpuesto contra una resolución de la Consejería de Obras Públicas de la Generalidad de Cataluña denegatoria de una solicitud de indemnización de los daños y perjuicios producidos al recurrente por la irregular tramitación de un plan urbanísticoº ${ }^{2}$

Se trataba, en efecto, de un Plan Especial que preveía la instalación de una residencia de la tercera edad en una zona de renovación urbana, plan cuya

2 Véase T. R. Fernández (2006), De la arbitrariedad de la Administración, Madrid: Thomson-Civitas, $5^{\mathrm{a}}$ ed., págs. 260 y sigs. 
aprobación inicial fue denegada por la Comisión Provincial de Urbanismo de Barcelona mediante resolución de 17 de junio de 1991, que fue anulada por sentencia de 9 de diciembre de 1995.

Presentado por el interesado un nuevo Plan Especial, la Comisión de Urbanismo lo aprobó definitivamente, pero dejó en suspenso la ejecutividad del acuerdo aprobatorio hasta que se cumplieran determinadas prescripciones, que fueron anuladas por sentencia de 9 de diciembre de 1996.

Tras dos sentencias favorables, pero inútiles, el promotor solicitó de la Administración de la Generalidad de Cataluña la indemnización de los daños y perjuicios que le había causado la irregular actuación de la Comisión de Urbanismo de Barcelona, cuya denegación fue impugnada en la vía contenciosoadministrativa por tercera vez.

La sentencia del Tribunal Superior de Justicia de la Generalidad de Cataluña volvió a dar la razón al promotor recurrente mediante sentencia de 1 de febrero de 2000 por entender que, en efecto, de la actuación de la Comisión Provincial de Urbanismo «se han derivado daños y perjuicios para la actora, de carácter antijurídico, que no estaba obligada a soportar y que no se hubieran producido si la CPUB hubiese actuado conforme a la normativa aplicable, como era su obligación».

La conclusión parecía irrebatible, pero la sentencia del Tribunal Supremo de 25 de mayo de 2004 no lo entendió así y revocó la sentencia de instancia con el pretexto, para mí incomprensible e inaceptable, de que, tratándose de actos discrecionales, no puede hablarse de lesión antijurídica, «siempre que el actuar de la Administración se mantuviese en unos márgenes de apreciación no solo razonados, sino razonables».

Este modo de razonar me dejó sencillamente estupefacto, por lo que no tuve más remedio que formular entonces mi protesta en los términos que siguen:

Que la Administración disponga de un poder discrecional y, por lo tanto, de unos ciertos márgenes de libertad decisoria, es muy importante, sin duda, a la hora de juzgar si la resolución adoptada en un supuesto determinado en ejercicio de dicho poder es o no conforme a Derecho. Pero una vez que un Tribunal ha decidido mediante sentencia firme que no lo es por no haber respetado esos márgenes o haber infringido de otro modo la Ley es obligado estar a las consecuencias.

La reclamación de responsabilidad patrimonial no abre una vía nueva para juzgar otra vez si la Administración respetó o no los márgenes de apreciación otorgados por la norma habilitante, como es notorio. Sorprende por ello en extremo que no lo haya entendido así la Sentencia que comento, cuya doctrina urge revisar para encajarla en su quicio, del que con toda evidencia se ha salido.

No insistí entonces más sobre el asunto porque pensé que la de 25 de mayo de 2004 a la que acabo de referirme era una sentencia aislada, que 
pronto quedaría en segundo plano. Estaba obviamente muy equivocado porque, como en aquel momento tenía el foco puesto en otro problema, no reparé en que esta sentencia se apoyaba en otra anterior, que calificaba de pionera, dictada el 5 de febrero de 1996 por la propia Sección 6a de la Sala 3a en la que se hacía una exposición detallada de la nueva doctrina que apoyaron todos los magistrados de la Sección, salvo el Sr. Peces Morate, que formuló un atinado y consistente voto particular al que luego haré también referencia.

El supuesto resuelto por esta sentencia de 5 de febrero de 1996, era bastante simple: el recurrente había solicitado la apertura de una oficina de farmacia al amparo de lo dispuesto en el art. 3 del Decreto 909/1978 entonces vigente, que contemplaba el supuesto excepcional de los núcleos de población de, al menos, 2.000 habitantes, solicitud que le fue finalmente denegada por el Consejo General de Colegios Oficiales de Farmacéuticos. Impugnada con éxito en la vía jurisdiccional la resolución denegatoria de la citada Corporación, el recurrente reclamó ante esta la indemnización correspondiente por los daños y perjuicios sufridos a consecuencia de la denegación de la autorización, pretensión que reiteró sin éxito ante el Tribunal Superior de Justicia de la Comunidad de Madrid y luego en casación ante el Tribunal Supremo, que declaró no haber lugar al recurso.

El asunto no parecía nada del otro mundo, porque el grueso de la reclamación se refería al lucro cesante, esto es, al beneficio neto que el recurrente hubiera podido obtener en el periodo comprendido entre la fecha en que el Consejo General de Colegio Oficiales de Farmacéuticos de España denegó la autorización de apertura de la farmacia y la de la sentencia que anuló dicha resolución, algo nada baladí desde luego, pero nada extraordinario tampoco.

Sin embargo, la sentencia de 5 de febrero de 1996 aprovechó la ocasión para dar una explicación completa - muy particular, por cierto- de nuestro sistema general de responsabilidad patrimonial de la Administración a resultas de la cual este ha resultado gravemente dañado. Conviene por ello repasarla con atención.

Comienza la sentencia formulando una afirmación más que discutible y que yo, desde luego, no comparto, a saber: que el principio de responsabilidad patrimonial proclamado en el art. 106 de la Constitución «conlleva un derecho de los llamados de configuración legal», que no deriva directamente de la Constitución, «sino que exige la interposición de una Ley y es exigible, no en los términos abstractos establecidos en la Constitución, sino en los términos concretos en que figure en la Ley ordinaria que lo regule porque tras la primera coma del párrafo transcrito se reconoce el derecho «en los términos establecidos por la Leym».

¿Quiere decir la sentencia que el legislador puede cambiar a voluntad el contenido y alcance de la garantía de indemnidad patrimonial frente al 
actuar lesivo de la Administración que el art. 106 de la Norma Fundamental proclama? ¿Quiere decir que puede ensanchar o reducir a discreción esa garantía? Confieso que no se me había ocurrido nunca tal cosa y que, más bien, había entendido siempre y sigo entendiendo que la constitucionalización de la cláusula general de responsabilidad patrimonial tenía justamente el sentido contrario, esto es, el de dar fijeza y estabilidad a una cláusula que se considera esencial en la medida en que asegura que nadie tenga que soportar a sus exclusivas expensas las consecuencias perjudiciales de una actividad, la administrativa, que se realiza en beneficio del conjunto de la comunidad.

Que al legislador corresponda precisar en qué forma y en qué plazo podrá ejercitarse el derecho a reclamar es una cosa y otra muy distinta que pueda disponer del contenido y el alcance de la garantía que la Constitución otorga y que la mayor o menor amplitud de esta quede a expensas de la aritmética parlamentaria. Para ese viaje no hacían falta, como es obvio, las alforjas constitucionales.

Tampoco es acertada la utilización que la sentencia hace de expresiones tales como «lesión antijurídica» o «antijuridicidad de la lesión», porque parece identificar el concepto técnico jurídico de lesión con el concepto material de perjuicio cuando lo cierto es que este se convierte en lesión cuando es antijurídico.

Subrayo esto porque está en la base, me parece, de la doctrina que la sentencia termina formulando, que literalmente es la siguiente:

En los supuestos de ejercicio de potestades discrecionales por la Administración, el legislador ha querido que ésta actúe libremente dentro de unos márgenes de apreciación con la sola exigencia de que se respeten los aspectos reglados que puedan existir, de tal manera que el actuar de la Administración no se convierta en arbitrariedad al estar ésta rechazada por el artículo 9.3 de la Constitución. En estos supuestos parece que no existiría duda de que siempre que el actuar de la Administración se mantuviese en unos márgenes de apreciación no sólo razonados sino razonables debería entenderse que no podría hablarse de lesión antijurídica, dado que el particular vendría obligado por la norma que otorga tales potestades discrecionales a soportar las consecuencias derivadas de su ejercicio siempre que éste se llevase a cabo en los términos antedichos; estaríamos pues ante un supuesto en el que existiría una obligación de soportar el posible resultado lesivo.

La misma doctrina entiende la sentencia que debe ser aplicada a aquellos casos en que la norma a aplicar por la Administración exija la apreciación de conceptos jurídicos indeterminados, ya que:

En tales supuestos es necesario reconocer un determinado margen de apreciación a la Administración que, en tanto en cuanto se ejercite dentro de márgenes razonados y razonables conforme a los criterios orientadores de la jurisprudencia 
y con absoluto respeto a los aspectos reglados que pudieran concurrir, haría desaparecer el carácter antijurídico de la lesión y por tanto faltaría uno de los requisitos exigidos con carácter general para que pueda operar el instituto de la responsabilidad patrimonial de la Administración.

Por si esto no estuviera claro, la sentencia añade un párrafo que quiere ser algo así como la prueba del nueve al precisar que:

Lo contrario podría incluso generar graves perjuicios al interés general al demorar el actuar de la Administración ante la permanente duda sobre la legalidad de sus resoluciones.

Y para terminar añade una advertencia sobre la necesidad de dar entrada en la valoración de los casos concretos a:

[...] datos de especial relevancia, cual sería la alteración o no de la situación jurídica en que el perjudicado estuviera antes de producirse la resolución anulada o su ejecución, ya que no puede afirmarse que se produzca tal alteración cuando la preexistencia del derecho no puede sostenerse al estar condicionado a la valoración, con un margen de apreciación subjetivo, por la Administración de un concepto en sí mismo indeterminado ${ }^{3}$.

Abierta así la brecha, la jurisprudencia posterior no ha dudado en consolidarla y ampliarla, como precisaré a continuación antes de abordar su crítica.

\section{LA EXTENSIÓN POSTERIOR DE LA JURISPRUDENCIA INICIAL: LAS SENTENCIAS DE 16 DE FEBRERO DE 2009 Y DE 20 DE FEBRERO DE 2012}

De los actos discrecionales «nulos, pero razonables» y las aplicaciones, también «nulas, pero razonables», de conceptos jurídicos indeterminados cuyas consecuencias lesivas tiene su destinatario el deber jurídico de soportar

3 La preexistencia o no de un derecho no tiene nada que ver, como es notorio, con la obligación de reparar los perjuicios que la Administración causa con sus actos a una persona. La empresa que acude a una licitación no tiene derecho alguno a que se le adjudique al contrato al que aspira, lo que obviamente no exonera a la Administración del deber de indemnizarla por los daños que para ella resulten del desistimiento del procedimiento de adjudicación o de la decisión de no adjudicar o celebrar el contrato (art. 152 de la Ley de Contratos del Sector Público de 8 de noviembre de 2017). Es solo un ejemplo entre muchos. 
pasa la sentencia de 16 de febrero de 2009 sin mayor dificultad a los «actos dictados en virtud de facultades absolutamente regladas» que, no obstante su anulación posterior, también imponen el «sacrificio individual» cuando tales facultades:

[...] se ejecuten dentro de los márgenes de razonabilidad que cabe esperar de una Administración pública llamada a satisfacer los intereses generales y que, por ende, no puede quedar paralizada ante el temor de que, si revisadas y anuladas sus decisiones, tenga que compensar al afectado con cargo a los presupuestos públicos, en todo caso, y con abstracción de las circunstancias concurrentes.

Como se observará, aquí ya no se trata de que la Administración tenga reconocido por la ley una libertad de apreciación que la permite, en principio, situarse en un punto u otro del espacio que aquella deja abierto, sino de algo totalmente distinto que no tiene amparo, ni siquiera aparente, en ley alguna, a saber: una supuesta libertad de interpretación, que, aunque no sirve para excluir la declaración de nulidad del acto resultante de un incorrecto ejercicio de la misma, sí exonera a la Administración del deber de indemnizar los perjuicios resultantes de dicho ejercicio cuando la interpretación realizada sea razonable.

La Sentencia es, en efecto, concluyente al respecto:

En definitiva, para apreciar si el detrimento patrimonial que supone para un administrado el funcionamiento de un determinado servicio público resulta antijurídico ha de analizarse la índole de la actividad administrativa y si responde a los parámetros de racionalidad exigibles. Esto es, si, pese a su anulación, la decisión administrativa refleja una interpretación razonable de las normas que aplica, enderezada a satisfacer los fines para lo que se la ha atribuido la potestad que ejercita. Así lo hemos expresado en las dos Sentencias referidas al 14 de Julio y 22 de Septiembre de 2008, dictadas en unificación de doctrina ${ }^{4}$.

4 Las sentencias de 14 de julio y 22 de septiembre de 2008 unifican la doctrina aplicable a las reclamaciones de los gastos consistentes en el pago de los honorarios profesionales a los abogados que asesoraron a los reclamantes en los conflictos que enfrentaron a estos con la Administración tributaria y que se resolvieron a su favor en la vía administrativa, asunto ciertamente parecido pero en absoluto idéntico al que se estudia en el texto, en el que media una sentencia firme, no una mera resolución administrativa, que anuló la decisión administrativa generadora de los honorarios abonados. El pago de los honorarios de abogado y procurador tiene su tratamiento específico en las normas procesales que regulan la condena en costas. Estas diferencias hacen abusiva e improcedente la cita de ambas sentencias en este caso. 
De parecido tenor es la sentencia de 20 de febrero de 2012, que cita y reproduce la anterior, aunque aporta un novum que merece ser resaltado, a saber: la anulación por sentencia firme de la resolución de la Confederación Hidrográfica del Guadiana que impuso determinadas limitaciones a la explotación de un acuífero se produjo por falta de motivación y de audiencia, pero «se hallaba materialmente amparada» por el art. 55 de la Ley de Aguas, por lo que, "pese a su anulación, la decisión administrativa refleja una interpretación razonable de las normas que aplica enderezada a satisfacer los fines para los que se ha atribuido la potestad que ejecuta».

Los vicios formales, aunque sea tan gruesos como la falta de motivación y la omisión del trámite de audiencia, pueden, sí, dar lugar a la anulación del acto administrativo, pero no son bastantes para generar el deber de resarcir el daño causado.

La lista sigue hasta hoy, pero la muestra ofrecida es, me parece, suficiente para darse cuenta de la magnitud del problema que esta jurisprudencia nos plantea.

Hemos llegado hasta aquí, además, sin darnos cuenta realmente de lo que estaba pasando porque estábamos contemplando, deslumbrados por su brillante luz, las palabras nuevas, que llenan actualmente el escenario de nuestra disciplina: globalización, regulación, sostenibilidad, transparencia, etc. Olvidamos al hacerlo que las dos vigas maestras que sostienen el edificio siguen siendo la legalidad y la responsabilidad y que sigue siendo cierta la conocida advertencia de M. Hauriou: que haga, pero que respete la ley; que haga, pero que pague el perjuicio 5 .

La Sala $3^{a}$ de nuestro Tribunal Supremo ha hecho un esfuerzo extraordinario para poner freno al ejercicio abusivo del poder discrecional y ha tenido un éxito notable en su empeño que es justo reconocer y que, desde luego, merece el mayor elogio, que yo nunca he regateado. Con el profundo respeto que su labor en este punto me produce y con el ánimo de corregir su deriva en este otro gran bloque de la responsabilidad patrimonial de la Administración, no tengo más remedio que criticar con la mayor energía la jurisprudencia que acabo de exponer, que, en mi opinión, es rigurosamente inaceptable y carece de todo fundamento, como a continuación intentaré justificar.

5 Véase M. Hauriou (1993), Précis de Droit Administratif, 12a ed., París, pág. 31. «Las dos principales teorías del Derecho Administrativo — dice el maestro tolosano en su Précis élémentaire de Droit Administratif, 5ª ed., París, 1943, pág. 17- son las del recurso contencioso-administrativo contra las decisiones ejecutorias de la Administración y las de las responsabilidades pecuniarias en que incurra la Administración en el ejercicio de su actividad». 


\section{ANÁLISIS CRÍTICO DE LA JURISPRUDENCIA}

\section{UN NUEVO SISTEMA DE RESPONSABILIDAD POR CULPA. Y POR CULPA GRAVE, ADEMÁS}

La sentencia de 5 de febrero de 1996 y las que siguen su huella empiezan por afirmar con el mayor énfasis que aceptan sin reservas la naturaleza objetiva de nuestro sistema de responsabilidad patrimonial de la Administración, afirmación esta que resulta radicalmente desmentida por el resultado — que es lo que importa- al que conduce la doctrina que establecen.

El voto particular formulado por el Sr. Peces Morate a la sentencia que inicia la serie supo verlo muy bien, pero se quedó corto, en mi opinión, al afirmar que el criterio de la mayoría situaba la responsabilidad derivada de la anulación de actos y resoluciones administrativas «fuera del ámbito de una auténtica responsabilidad objetiva o por el resultado, aproximándola a la responsabilidad por culpa», porque, más que aproximarla, la verdad es que la sitúa de lleno en el ámbito de esta última y va incluso un paso más allá porque hace depender el reconocimiento del deber de la Administración de resarcir el daño causado por sus resoluciones de la existencia no ya de una infracción cualquiera del ordenamiento jurídico, que alguna tuvo que haber para que un Tribunal anulara dichas resoluciones, sino de un error grosero, de una arbitrariedad patente, de una aplicación irracional o irrazonable del derecho material o sustantivo. Recuérdense los términos de la sentencia de 20 de febrero de 2012 más atrás citada, que no consideró suficientes a los efectos de generar el deber de resarcimiento ni la falta de motivación, ni la omisión del trámite de audiencia porque la decisión adoptada «se hallaba materialmente amparada» por el art. 55 de la Ley de Aguas.

Hace falta, pues, una actuación viciada de culpa, pero de una culpa grave o gravísima para que la pretensión de resarcimiento pueda prosperar. Si no hay una culpa de esta naturaleza, el destinatario del acto anulado tiene el deber jurídico de soportar el perjuicio que le haya inferido dicho acto.

Estoy escribiendo esto y me parece mentira realmente que el más Alto Tribunal del país haya podido decir algo semejante. ¿Acaso no dice la ley que da lugar en todo caso a indemnización la anulación de los títulos administrativos habilitantes de obras y actividades, así como la demora injustificada y su denegación improcedente? El art. 48 del texto refundido de la Ley de Suelo de 30 de octubre de 2015 no puede ser más categórico al respecto. La procedencia de la indemnización en tales casos no se subordina en absoluto a la razonabilidad mayor o menor de la resolución denegatoria. Muy al contrario, la indemnización solo se excluye «si existe dolo, culpa o negligencia graves imputables al perjudicado». 
¿Cómo puede encajarse el precepto citado con la jurisprudencia a la que me vengo refiriendo que está exactamente en sus antípodas? Y, sobre todo, ¿cómo puede afirmarse con tanto énfasis que el nuestro es un sistema de responsabilidad objetiva y sostener al mismo tiempo una doctrina que exige la existencia de una irregularidad grosera, de una falta total de razonabilidad del acto lesivo? ¿Dónde está o cuál es el argumento que le permite a esta jurisprudencia compatibilizar posiciones tan rabiosamente contradictorias?

En la formulación de la sentencia primera de 5 de febrero de 1996, que las posteriores se limitan a repetir, la explicación parece estar en una concepción errónea de la discrecionalidad como margen de libertad que la norma habilitante otorga a la Administración apoderada, que permite a esta situarse en cualquier punto del espacio así creado, lo que parece llevar consigo que el destinatario de su decisión tiene el deber jurídico de soportar las consecuencias de dicha decisión en todo caso, ya que, cualquiera que sea el punto elegido, todos los situados dentro de ese espacio de libertad son indiferentes jurídicamente.

Así se desprende, sin duda, del fundamento tercero de la sentencia en el que esta afirma que «en los supuestos de ejercicio de potestades discrecionales por la Administración, el legislador ha querido que ésta actúe libremente dentro de unos márgenes de apreciación, con la sola exigencia de que se respeten los aspectos reglados que puedan existir, de tal manera que el actuar de la Administración no se convierta en arbitrariedad al estar ésta rechazada por el artículo 9.3 de la Constitución», lo que le lleva a concluir que en estos supuestos «parece que no existiría duda de que siempre que el actuar de la Administración se mantuviese en unos márgenes de apreciación no sólo razonados, sino razonables, debería entenderse que no podría hablarse de existencia, de lesión antijurídica, dado que el particular vendría obligado por la norma que otorga tales potestades discrecionales a soportar las consecuencias derivadas de su ejercicio».

Con todo respeto no tengo más remedio que decir que esto no es, ni puede ser, así. Vamos a ver por qué.

\section{UNA CONTRADICCIÓN EN LOS TÉRMINOS}

Que el poder discrecional pone a disposición de la Administración apoderada un espacio de libertad dentro del cual puede esta escoger la solución que considere más adecuada a las circunstancias es una obviedad. Y lo es también que todas las soluciones situadas dentro de ese espacio son, en principio, indiferentes desde el punto de vista jurídico. Así se viene diciendo desde siempre, aunque el empleo del adjetivo indiferente sea profundamente equívoco, porque ese calificativo solo puede otorgarse a posteriori, una vez valorada en su contexto la solución de la que en cada caso se trate. Por eso subrayo la expresión «en principio». 
La libertad de elegir una solución de entre las varias posibles ab initio es limitada o, mejor dicho, condicionada. ¿A qué? A la existencia de una justificación suficiente, es decir, de razones objetivas, consistentes con la realidad y exteriormente verificables capaces de dar soporte a la elección. Si esas razones no existen o no se dan, ya no estaremos en presencia de un ejercicio legítimo de la discrecionalidad, sino en el ámbito oscuro de la arbitrariedad constitucionalmente prohibida. La existencia de razones, no de cualesquiera argumentos, sino de razones consistentes es la línea divisoria que separa la discrecionalidad de la arbitrariedad, como la propia jurisprudencia de la Sala $3^{a}$ del Tribunal Supremo acertó a señalar recién estrenada la Constitución felizmente vigente.

No voy a insistir más, como es natural, sobre lo que yo mismo he escrito tantas veces en el último cuarto de siglo ${ }^{6}$, pero sí quiero recordar una vez más una sentencia ejemplar, la de 13 de julio de 1984, una de las primeras que abrieron ese nuevo camino, cuyos términos son para mí definitivos. Dice así:

[...] nunca es permitido confundir lo discrecional con lo arbitrario, pues aquello se halla o debe hallarse cubierto por motivaciones suficientes, discutibles o no, pero considerables en todo caso, y no meramente de una calidad que los haga inatacables, mientras que lo segundo o no tiene motivación respetable, sino - pura y simplemente- la conocida sit pro rationes voluntas o la que ofrece lo es tal que, escudrińando su entraña, denota a poco esfuerzo de contrastación, su carácter de realmente indefinible y su inautenticidad.

Lo que distingue lo discrecional de lo arbitrario son, pues, las razones, que pueden ser, ciertamente, discutibles, pero que si están bien fundadas y son consistentes con la realidad de los hechos hacen inatacable el acto que en ellas se apoya. Si hay razones, buenas razones, el acto discrecional no podrá ser anulado por un tribunal y, si lo ha sido, es sin duda porque tales razones faltaban. Tertium non datur.

Un acto discrecional no puede ser al mismo tiempo nulo y razonable. Afirmarlo así, como lo hace la jurisprudencia que analizamos, implica una contradicción en los términos, un imposible lógico. Si el acto lesivo fue declarado nulo por sentencia firme es porque el tribunal que dictó esa sentencia no encontró razones que pudieran sostenerlo. Es, pues, jurídicamente imposible afirmar luego, cuando se reclame la compensación de los dańos producidos, que el acto en cuestión era nulo, pero que era un acto razonado y razonable,

6 Y muy recientemente en T. R. Fernández (2016), Arbitrario, arbitraire, arbitrary. Pasado y presente de un adjetivo imprescindible en el discurso jurídico, Madrid: Iustel. 
porque esto ya quedó descartado por una sentencia firme anterior y es, por lo tanto, cosa juzgada.

\section{UNA FLAGRANTE VIOLACIÓN DE LA SANTIDAD DE LA COSA JUZGADA}

Este modo de operar implica, en efecto, una flagrante violación de la santidad de la cosa juzgada, puesto que se aprovecha la apertura de un nuevo proceso para reclamar la indemnización de los daños y perjuicios causados por el acto previamente declarado nulo como una oportunidad para juzgar otra vez si al dictar aquel acto, la Administración respetó o no los márgenes de apreciación otorgados por la norma habilitante.

Por sorprendente que parezca, eso es lo que hacen sistemáticamente sin el menor empacho las sentencias que analizamos. En el supuesto resuelto por la sentencia de 5 de febrero de 1996, el Colegio Provincial de Farmacéuticos había autorizado al recurrente la apertura de una oficina de farmacia al amparo del artículo 3.1.b) del Decreto 909/1978 por entender que se estaba en presencia de un núcleo de población de al menos 2.000 habitantes. Esta resolución fue anulada por el Consejo General de Colegios de Farmacéuticos de España en base a una interpretación distinta del concepto de núcleo de población, lo que terminó con una sentencia del Tribunal Supremo que anuló la resolución del Consejo General y confirmó, en consecuencia, la del Colegio Provincial. Quedó, pues, decidido en firme que existía, en efecto, un núcleo de población de 2.000 habitantes.

Pues bien, la sentencia de 5 de febrero de 1996 vuelve sobre el tema y no duda en corregir ese juicio firme anterior en unos términos realmente sorprendentes, que no tengo más remedio que transcribir porque, de no hacerlo, podría no ser creído por los lectores. Dice así la sentencia en su fundamento jurídico cuarto a propósito de la indeterminación en el caso concreto del concepto de núcleo de población:

[...] indeterminación que se pone especialmente de relieve tras la lectura del acta de inspección ocular llevada a cabo por el Colegio Farmacéutico en vía administrativa, en la que, tras afirmar la desaparición de los primitivos accidentes naturales, se afirma de forma absolutamente dubitativa la posibilidad de considerar como obstáculo la avenida existente con zona central ajardinada, razón esta por la que ha de concluirse que la valoración que se efectúa en la resolución anulada por parte de la Administración de los datos obrantes en su poder a efectos de integrar el concepto indeterminado contenido en la norma, se ha operado con arreglo a los criterios exigibles conforme a lo manifestado en los fundamentos anteriores para excluir la antijuricidad de la posible lesión, como lo confirma el hecho de que tal resolución se viese ratificada en la primera instancia jurisdiccional, afirmando la Sentencia del Tribunal Superior de Justicia de Canarias de fecha 6 junio 1987, 
que «la estructuración del viario y del tráfico peatonal y urbano, hace imposible hablar de separación dentro de la zona, o de células o núcleos distintos, pues se trata de un conglomerado urbano, con todos los servicios comunes, siendo fácil los desplazamientos de un punto a otro, a través de aceras, pasos peatonales con señalización semafórica o policial».

Una revisión en toda regla, como puede verse, del juicio firme expresado por la sentencia anterior del propio Tribunal Supremo que declaró la nulidad del acuerdo denegatorio de la autorización del Consejo General de Colegios de Farmacéuticos, revisión que se apoya, incluso, iiien la Sentencia del Tribunal Superior de Justicia de Canarias que aquella revocó!!!

La sentencia de 25 de mayo de 2004 tampoco tiene ningún reparo en volver a enjuiciar los actos administrativos anulados por sendas sentencias firmes y en corregir francamente el juicio emitido por estas «pues no se puede desconocer — dice- que el suelo sobre el que se proyectaba construir aquella residencia geriátrica estaba calificado de equipamiento de titularidad pública y no de mero destino residencial. En definitiva - concluye-, tales prescripciones (las anuladas en firme por la Sentencia que decidió el segundo proceso) eran no sólo acordes con sus potestades administrativas, sino que también se encuadraban dentro de los márgenes de apreciación de la lógica natural que conlleva el ejercicio de la potestad tradicional».

$\mathrm{Y}$ así siempre que la anulación por sentencia firme del acto lesivo se produjo por razones de fondo, que, si fueron de forma, simplemente se consideran intranscendentes, se desprecian, como lo hace la sentencia de 20 de febrero de 2012.

No creo que esta acción de volver a juzgar lo ya juzgado y corregir incluso el juicio firme ya pronunciado requiera ningún comentario crítico más allá de su mera exposición. ¡Es tan evidente que no puede hacerse algo así!

\section{LA LEY DEL EMBUDO}

Con razón dijo Hans Huber que la discrecionalidad «es el caballo de Troya dentro del Estado de Derecho». No hay más que ver los destrozos que ha producido la adopción de una actitud condescendiente con ella, destrozos que no se han quedado aquí, porque, como ya dije, se empezó excluyendo el resarcimiento de los daños producidos por actos discrecionales declarados nulos por sentencia firme porque, pese a su nulidad, eran razonables y el entusiasmo liberador ha terminado por excluir también la compensación de los daños derivados de actos estrictamente reglados cuando dichos actos, aunque nulos, resultan de una interpretación razonable de las normas de aplicación. 
A esto último renuncio a hacer comentario alguno. Solo diré que no he visto nunca aplicar doctrina tan comprensiva cuando es el particular el que no respeta estrictamente la ley, pero actúa de acuerdo con una aplicación razonable de esta. Si así fuese, los abogados ganaríamos todos los pleitos sin excepción, ya que, en general, sabemos razonar bien e, incluso, muy bien para justificar la posición adoptada por nuestros clientes.

Esto es lo que hay, sin embargo. De la responsabilidad por actos y resoluciones no queda, pues, prácticamente nada, ya que solo pueden generarla, según la jurisprudencia estudiada, los actos manifiestamente arbitrarios por excesivos, desproporcionados o carentes de justificación objetiva, si es que, llegado el caso, en ese segundo juicio que se permite abrir con motivo de la reclamación de responsabilidad no se encuentra para ellos algún nuevo paliativo.

En todos los demás casos los perjuicios que nos hayan podido producir los actos de la Administración declarados contrarios a derecho por sentencia firme no son perjuicios antijurídicos, porque, de acuerdo con esta jurisprudencia, los ciudadanos tenemos el deber jurídico de soportarlos.

Ninguna ley, ni constitucional ni ordinaria, establece semejante deber, por supuesto, pero es que «lo contrario — dice la sentencia pionera de 5 de febrero de 1996 - podría incluso generar graves perjuicios al interés general al demorar el actuar de la Administración ante la permanente duda sobre la legalidad de sus resoluciones» ${ }^{7}$.

¿De verdad cree eso la Sala $3^{\text {a }}$ del Tribunal Supremo? Porque si es así, si el derecho administrativo tiene que hacerse a un lado para que la Administración no viva en una permanente duda sobre la legalidad de sus actos, sobramos todos.

Es muy grave realmente lo que está ocurriendo y exige con urgencia una reflexión a fondo y una corrección sustancial, que en cualquier caso tiene que dejar bien claro que ningún ciudadano tiene el deber jurídico de soportar las consecuencias perjudiciales de un acto de la Administración que ha sido declarado contrario a derecho por sentencia firme. Como dijo muy bien el voto particular del Sr. Peces Morate a la sentencia de 5 de febrero de 1996, «no cabe duda de que la Administración cuando decide está haciendo uso de una potestad al mismo tiempo que cumpliendo un deber, pero para quedar amparada su actuación por una causa de justificación que la exonere de responsabilidad ha de resolver conforme a Derecho, porque su actuación está sometida a la

7 En términos parecidos se expresan otras sentencias de la serie. Así, la sentencia de 20 de febrero de 2012 advierte que la Administración «no puede quedar paralizada ante el temor de que, revisadas y anuladas, en su caso, sus decisiones, tenga que compensar al afectado con cargo a los presupuestos públicos en todo caso y con abstracción de las circunstancias concurrentes». 
Ley y al Derecho (artículos 103.1 de la Constitución y 3.1 de la Ley 30/1992, de 26 de Noviembre, de las Administraciones Públicas y del Procedimiento Administrativo Común). Sólo cuando así se pronuncie el daño no será antijurídico, pues el perjudicado por una decisión contraria a Derecho no tiene el deber de soportarlo». 
